\title{
Simultaneous Presentation of Ankylosing Spondylitis and Pancreatic Cancer: A Case Report
}

\author{
Ekaterina V. Kapustina, $\mathrm{PhD}^{1^{*}}$; Gennady P. Bulygin ${ }^{2}$; Vasily S. Mordovsky ${ }^{1}$; Tatyana V. \\ Potupchik, $\mathrm{PhD}^{1}$; Svetlana Yu. Nikulina, $\mathrm{PhD}, \mathrm{ScD}^{1}$; Anna A. Chernova, $\mathrm{PhD}, \mathrm{ScD}^{1}$; \\ Denis A. Medvedev'; ; Andrey M. Budarev²; Vera A. Chupakhina, $\mathrm{PhD}^{1}$; \\ Tatyana Yu. Bolshakova, $\mathrm{PhD}^{1}$; Elena P. Kluchnikova $\mathrm{PhD}^{3}$ \\ 'Professor V.F. Voino-Yasenetsky Krasnoyarsk State Medical University \\ ${ }^{2}$ Krasnoyarsk Regional Clinical Oncologic Dispensary n.a. A.I. Kryzhanovsky \\ ${ }^{3} K G B U Z$ "Regional Clinical Hospital" \\ Krasnoyarsk, the Russian Federation
}

\begin{abstract}
A clinical case of simultaneous presentation of ankylosing spondylitis and pancreatic cancer is described. Patients with rheumatic disorders must be closely followed to screen for malignancies. Most paraneoplastic rheumatic syndromes are difficult to distinguish from autoimmune rheumatic diseases; thus, cancer occurrence may constitute a major diagnostic challenge.
\end{abstract} (International Journal of Biomedicine. 2019;9(1):69-71.)

Key Words: ankylosing spondylitis • pancreatic cancer • paraneoplastic rheumatic syndromes

\section{Abbreviations}

AS, ankylosing spondylitis; ARDs, autoimmune rheumatic diseases; NSAIDs, nonsteroidal anti-inflammatory drugs; PRS, paraneoplastic rheumatic syndromes.

\section{Introduction}

Several studies have indicated connections between malignancy and autoimmune rheumatic diseases. ${ }^{(1-4)}$ During the past 30 years there have been many attempts to determine more precisely the link between cancer and rheumatic disorders. The explanation of this association remains unclear. Rheumatic syndromes may be associated with malignancy as paraneoplastic conditions, which can antedate the neoplasm diagnosis. On the other hand, autoimmune rheumatic diseases (ARDs) have a higher risk of malignancy by themselves or

*Corresponding author: Assistant Professor Ekaterina $V$. Kapustina, PhD. Professor V.F. Voino-Yasenetsky Krasnoyarsk State Medical University. Krasnoyarsk, the Russian Federation. E-mail: as-pirinka5@yandex.ru because of the immunosuppressant treatments. Malignancies are associated with a wide variety of paraneoplastic rheumatic manifestations, which may arise in joints, fasciae, muscles, vessels or bones. ${ }^{(5,6)}$ The pathogenesis of paraneoplastic rheumatic syndromes (PRS) is complex and not fully understood in the majority of instances. Rheumatic syndromes can be important clues to occult neoplasia. ${ }^{(3,7)}$ Approximately $15 \%$ of patients with cancer develop paraneoplastic syndromes as a result of tumor-derived biologic mediators like hormones, peptides, antibodies, cytotoxic lymphocytes, autocrine and paracrine mediators. ${ }^{(5,8)}$

Until now, little has been understood regarding the pathogenesis of connective tissue diseases in association with neoplastic disease. Several factors, including autoimmune disease itself, common etiology between ARDs and malignancy, including genetic factors, viruses and 
smoking, have been implicated in the pathogenesis of tumor development. ${ }^{(9)}$ Epidemiological studies have revealed that patients with chronic inflammation are at increased risk of developing cancer. ${ }^{(10,11)}$ Pathologically, chemokines, cytokines and prostaglandins are able to shift the microenvironment of an organ from a healthy to a dysplastic state, which favors malignant changes in affected cells. ${ }^{(11)}$ Elevated serum interleukin (IL)-1, IL-6, and TNF- $\alpha$ levels trigger inflammatory reactions in patients with spondyloarthritis. ${ }^{(12)}$

Chang et al., ${ }^{(13)}$ using the Taiwan National Health Insurance Research Database, have analyzed the data from patients diagnosed with AS between 2000 and 2008 who had no history of cancer prior to enrollment $(n=5,452)$. Ageand sex-matched patients without AS served as controls $(n=21,808)$. The results revealed that the overall incidence of cancer was elevated in AS patients (SIR 1.15; 95\% CI 1.031.27). The cancer risk was increased during the first 3 years following the diagnosis of AS. In another study, Feltelius et al. ${ }^{(14)}$ concluded that AS does not affect the overall cancer risk in Sweden. In studies reported by Hemminki et al., AS patients in Sweden showed an increased risk for multiple myeloma, ${ }^{(15)}$ a decreased risk for digestive tract cancer, ${ }^{(16)}$ and no altered risk for non-Hodgkin lymphoma. ${ }^{(17)}$ In female cancer types of the breast, uterus, ovary and other genital organs, a low standardized incidence ratio (SIR) in female patients with AS was noted. ${ }^{(18)}$ Thus, the potential association between AS and cancer is controversial.

\section{Case presentation}

A 34-year-old woman with severe pain in the upper abdomen that radiated to the back and was diagnosed with obstructive jaundice, was hospitalized in the surgical department (Clinical Emergency Hospital n.a. N.S. Karpovich). A biochemical blood test was performed and cytolysis syndrome was detected (increased ALT/AST up to three norms). Esophagogastroduodenoscopy showed a tumor-like formation with ulcerations in the area of the major duodenal papilla. The debut of articular syndrome with the development of pain and swelling, and severe stiffness in the knee joints, was registered in April 2018. Therapy for AS included NSAIDs (ketoprofen orally and topically) and parenteral glucocorticoids. It was possible to reduce the severity of articular syndrome only for a short time. In the same month, with suspicions that there were malignant tumors of the major duodenal papilla and pancreas, the patient was referred to the oncologic dispensary n.a. A.I. Kryzhanovsky.

The patient underwent gastropancreaticoduodenectomy with a histological examination of the removed material. The histological study detected a moderately differentiated pancreatic adenocarcinoma with invasion into the duodenal wall up to the mucosa. On the fifth day after the operation, the patient noted the return of pain and swelling in the knee joints. Nonsteroidal anti-inflammatory drugs and parenteral glucocorticoids were also included in the treatment regimen. Taking into account that her sister suffered from AS, the patient was examined by a rheumatologist at the place of residence. The examination confirmed the following: X-ray of the sacroiliac joints: bilateral grade 3 sacroiliitis. Multislice computed tomographyof the pelvic bones: bilateral erosive sacroiliitis. In addition, the patient was HLA-B27 positive. Sulfasalazine $(2,000 \mathrm{mg})$, prednisolone $(20 \mathrm{mg})$, and etoricoxib (90 mg) were additionally included in the treatment regimen. On the background of treatment, the pain and swelling of the knee joints and morning stiffness have decreased. The dose of prednisolone was reduced to $10 \mathrm{mg}$.

\section{Conclusion}

According to the clinical, instrumental and laboratory examinations, this patient simultaneously suffered from two diseases: pancreatic cancer and ankylosing spondylitis. The development of the latter can hardly be called paraneoplastic syndrome, since erosive sacroiliitis and HLA-B27 were detected. Recognizing that a relationship exists between malignancy and rheumatic diseases is important to our future understanding of the pathogenesis of the two entities. ${ }^{(5)}$ Patients with rheumatic disorders must be closely followed to screen for malignancies. Most paraneoplastic rheumatic syndromes are difficult to distinguish from autoimmune rheumatic diseases; thus, cancer occurrence may constitute a major diagnostic challenge. Early detection and therapy may be of utmost clinical importance.

\section{Competing Interests} interests.

The authors declare that they have no competing

\section{References}

1. Wen J, Ouyang H, Yang R, Bo L, Zhang Y, Tang M, Liu Z.Malignancy dominated with rheumatic manifestations: A retrospective single-center analysis. Sci Rep. 2018;8(1):1786. doi: 10.1038/s41598-018-20167-w.

2. Bellan M, Boggio E, Sola D, Gibbin A, Gualerzi A, Favretto S, et al. Association between rheumatic diseases and cancer: results from a clinical practice cohort study. Intern Emerg Med. 2017;12(5):621-627. doi: 10.1007/s11739-0171626-8.

3. Manger B, Schett G. Rheumatic paraneoplastic syndromes - A clinical link between malignancy and autoimmunity. Clin Immunol. 2018;186:67-70. doi: 10.1016/j.clim.2017.07.021.

4. Turesson C, Matteson EL. Malignancy as a comorbidity in rheumatic diseases. Rheumatology (Oxford). 2013;52(1):514. doi: 10.1093/rheumatology/kes189.

5. Bojinca V, Janta I. Rheumatic diseases and malignancies. Maedica (Buchar). 2012;7(4):364-71.

6. Azar L, Khasnis A. Paraneoplastic rheumatologic syndromes. Curr Opin Rheumatol. 2013;25(1):44-9. doi: 10.1097/BOR.0b013e328359e780.

7. Naschitz JE. Rheumatic syndromes: clues to occult neoplasia.Curr Opin Rheumatol. 2001 Jan;13(1):62-6

8. Szekanecz E, András C, Sándor Z, Antal-Szalmás P, Szántó J, Tamási L, et al. Malignancies and soluble tumor antigens in rheumatic diseases. Autoimmun Rev. 2006;6(1):42-7.

9. Szekanecz Z, Szekanecz E, Bakó G, Shoenfeld Y. Malignancies in autoimmune rheumatic diseases-a mini-review. Gerontology. 2011;57(1):3-10. doi: 10.1159/000314634. 
10. Mantovani A, Allavena P, Sica A, Balkwill F.Cancerrelated inflammation. Nature. 2008;454(7203):436-44. doi: 10.1038/nature07205.

11. Balkwill F, Mantovani A. Inflammation and cancer: back to Virchow? Lancet. 2001;357(9255):539-45.

12. Hreggvidsdottir HS, Noordenbos T, Baeten DL. Inflammatory pathways in spondyloarthritis. Mol Immunol. 2014;57(1):28-37. doi: 10.1016/j.molimm.2013.07.016.

13. Chang CC, Chang CW, Nguyen PA, Chang TH, Shih YL, Chang WY, et al. Ankylosing spondylitis and the risk of cancer. Oncol Lett. 2017;14(2):1315-1322. doi: 10.3892/ ol.2017.6368.

14. Feltelius N, Ekbom A, Blomqvist P. Cancer incidence among patients with ankylosing spondylitis in Sweden 1965-95: a population based cohort study. Ann Rheum Dis. 2003;62(12):1185-8.
15. Hemminki K, Liu X, Försti A, Ji J, Sundquist J, Sundquist $\mathrm{K}$. Effect of autoimmune diseases on incidence and survival in subsequent multiple myeloma. J Hematol Oncol. 2012;5:59. doi: 10.1186/1756-8722-5-59.

16. Hemminki K1, Liu X, Ji J, Sundquist J, Sundquist K. Autoimmune disease and subsequent digestive tract cancer by histology. Ann Oncol. 2012;23(4):927-33. doi: 10.1093/ annonc/mdr333.

17. Fallah M, Liu X, Ji J, Försti A, Sundquist K, Hemminki K. Autoimmune diseases associated with non-Hodgkin lymphoma: a nationwide cohort study. Ann Oncol. 2014;25(10):2025-30. doi: 10.1093/annonc/mdu365.

18. Hemminki K, Liu X, Ji J, Försti A, Sundquist J, Sundquist $\mathrm{K}$. Effect of autoimmune diseases on risk and survival in female cancers. Gynecol Oncol. 2012;127(1):180-5. doi: 10.1016/j.ygyno.2012.07.100. 